39 (2) $\mid 2010$

Varia

\title{
Presentación
}

\section{Carole Fraresso}

\section{OpenEdition}

\section{Journals}

Edición electrónica

URL: http://journals.openedition.org/bifea/1883

DOI: 10.4000/bifea.1883

ISSN: 2076-5827

\section{Editor}

Institut Français d'Études Andines

\section{Edición impresa}

Fecha de publicación: 1 agosto 2010

Paginación: 221-223

ISSN: 0303-7495

\section{Referencia electrónica}

Carole Fraresso, «Presentación », Bulletin de l'Institut français d'études andines [En línea], 39 (2) | 2010,

Publicado el 01 febrero 2011, consultado el 07 noviembre 2020. URL : http://journals.openedition.org/ bifea/1883 ; DOI : https://doi.org/10.4000/bifea.1883

\section{(c) (i) (9)}

Les contenus du Bulletin de l'Institut français d'études andines sont mis à disposition selon les termes de la licence Creative Commons Attribution - Pas d'Utilisation Commerciale - Pas de Modification 4.0 International. 


\section{Contextos, MATERIALES E IDENTIDADES EN LA ARQUEOLOGÍA MOCHICA}





\section{Presentación}

En el marco del 50 aniversario del hermanamiento entre Lima y Bordeaux, se publican a continuación las actas de la Mesa redonda internacional «Contextos, materiales e identidades en la arqueología Mochica», que tuvo lugar en el Institut de Recherche sur les Archéomatériaux IRAMAT-CRP2A UMR5060-CNRS de la universidad de Bordeaux (Francia), del 23 al 24 de octubre de 2007. Si el IFEA siempre tuvo a bien apoyar la arqueología andina, también supo promover un enfoque que conjugara los métodos tradicionales de la Arqueología con los métodos modernos de la ciencia de los materiales. Vale mencionar aquí los temas de investigación vinculados a la disciplina de los arqueomateriales, ya sean ecofactos (carbón de madera, osamenta humana y animal, etc.) o artefactos (metales, cerámica, pigmentos, etc.), que han desarrollado varios jóvenes investigadores del IFEA tales como Tania Delabarde, Fanny Moutarde, Carole Fraresso, Véronique Wright, Nicolas Goepfert y Agnès Rohfritsch.

La caracterización de los materiales arqueológicos no es un fin en sí; pero permite, a partir de la «lectura tecnológica» de los artefactos, acceder a informaciones privilegiadas. Por ejemplo, los datos analíticos son idóneos para identificar materiales y procesos; sin embargo, junto con los datos arqueológicos abren otras perspectivas de reflexión. Más allá de los análisis propiamente dichos, esta pluridisciplinaridad, acarreada por la colaboración entre arqueólogos y arqueómetros, permite definir unos facies culturales y fecharlos en contextos bien definidos. También, ofrece la posibilidad de reflexionar sobre aspectos propios a la organización artesanal y aproximarse a las posibles vías de intercambios entre diferentes sitios. Por ende, este enfoque responde a problemáticas arqueológicas precisas que hacen avanzar la comprensión global de la organización y de los modos de funcionamiento sociopolíticos, tecnológicos y culturales de las sociedades precolombinas.

Para ilustrar la diversidad de los temas que nos preocupan, y sobre los cuales se debe seguir reflexionando, hemos centrado nuestras discusiones en el estudio de varias categorías de materiales arqueológicos propios de la cultura Mochica 
(150-850 d.C.), con el fin de iniciar el estudio de las características que definen la «Cultura técnica» de esta gran sociedad «artística» de la costa norte del Perú.

En los últimos 20 años, la arqueología Mochica ha alcanzado mayor visibilidad gracias a espectaculares hallazgos de tumbas de gobernantes y altos dignatarios, de monumentales templos decorados con pinturas murales pero también de ciudades y pueblos donde las personas vivían y producían una amplia gama de productos. Las investigaciones han revelado que el sistema de organización política y social de esta sociedad no había formado un estado centralizado, sino un conjunto de entidades políticas regionales y locales con modelos de desarrollo político, ideológico y económico - ¿y técnicos? - muy diferentes, a partir de los cuales se habían forjado tradiciones culturales independientes. Estamos entonces confrontados al estudio de instituciones políticas y sociales múltiples unidas entre sí por un sistema religioso común y relaciones de intercambios y rivalidades más o menos intensas, pero no necesariamente lineales durante sus siete siglos de historia. Con esta ocasión, los organizadores de este evento (Carole Fraresso, Michel Pernot y Luis Jaime Castillo) invitaron a proponer nuevas aproximaciones metodológicas para distinguir, en esta sociedad, lo «común» de lo «singular». Esto implicaba transformar nuestra aproximación al estudio de aspectos muy generales, como la religión y la organización social, hasta el análisis de elementos más particulares como las «tecnologías» y los estilos artísticos. Los vestigios materiales de las actividades humanas, que tienen formas, dimensiones, decoraciones y que son constituidos por varios materiales, son testigos tangibles que constituyen un elemento fundamental para el estudio arqueológico de las identidades regionales y/o locales.

Contextos, materiales e identidades son los temas centrales que han sido discutidos en este evento. La Arqueología (Luis Jaime Castillo, Santiago Uceda, Christopher Donnan, Jeffrey Quilter, Anne-Marie Hocquenghem), la zooarqueología (Nicolas Goepfert), la ceramología (Agnés Rohfritsch), la historia de la técnicas (AnneFrançoise Garçon), la metalurgia (Michel Pernot, Carole Fraresso) así como las tecnologías textiles (Sophie Desrosier) y las pictóricas de murales (Véronique Wright) fueron las disciplinas seguidas para promover una metodología «transdisciplinaria» apta a la interpretación del desarrollo político y a la formación de la(s) identidad(es) de la sociedad Mochica.

La presente publicación muestra claramente cúan importantes son los estudios arqueométricos para responder a las interrogantes actuales de la Arqueología. Más allá permitirán, en el futuro, definir la(s) «Cultura(s) técnica(s)» de las sociedades precolombinas, lo que hasta hoy despertó poco interés. Las diferentes contribuciones presentadas en el Boletín del IFEA aportan por ejemplo referencias, metodológicas y analíticas, que mejoran la comprensión de la «Cultura técnica» Mochica. La Mesa redonda de Bordeaux no quiso lucir por su aparato, sino valorar la amistad y la colaboración transdisciplinaria de varios años. Al romper, de cierta manera, con la división académica que separa habitualmente las ciencias humanas y las ciencias duras, hemos logrado abrir un nuevo espacio de discusiones que entusiasmó tanto a los investigadores como a los estudiantes. Por 
lo tanto, lamentamos que varios artículos no hayan podido ser integrados en esta publicación; también nos hubiera gustado invitar a un conjunto más amplio de colegas «mochicologos», pero anhelamos que nuestras reflexiones sean nutridas por futuras discusiones.

Quisiéramos agradecer, a nuestra colega Luis Jaime Castillo, de la Pontificia Universidad Católica del Perú, por haber coorganizado este evento, así como a Pierre Guibert, director del Institut de Recherche sur les Arqueomatériaux, y todo el equipo del laboratorio bordelés, por apoyarnos y acogernos en sus instalaciones. Agradecemos de manera especial a Michel Pernot, por su disponibilidad constante en la organización de nuestra Mesa redonda.

También quisiéramos agradecer el apoyo brindado por diferentes instituciones francesas y peruanas: la universidad Michel de Montaigne de Bordeaux-CNRS, la red «Raúl Porras Barrenechea», la Cooperación Universitaria de la Embajada de Francia, en Lima, la Pontificia Universidad Católica del Perú de Lima, el Instituto Francés de Estudios Andinos de Lima (IFEA), el Consejo Regional de Aquitania y las alcaldías de Bordeaux y Lima.

Finalmente reiteramos nuestro agradecimiento al IFEA, a su ex director, Henri Godard por haber apoyado la realización de este evento científico y a su director actual, Georges Lomné, por ofrecernos la oportunidad de publicar los resultados de nuestros debates en el Bulletin del IFEA. También agradecemos al personal por su constante apoyo logístico y a Anne-Marie Brougère, encargada de la edición, por la atenta y eficiente preparación de esta publicación.

\section{Carole FRARESSO*}

* Investigadora asociada al IFEA. E-mail: fraressocarole@yahoo.fr 